\title{
Description of saturation curves and boiling process of dry air
}

\author{
Magda Vestfálová1, ${ }^{*}$, Markéta Petř́ková1, Martin Šimko ${ }^{1}$ \\ ${ }^{1}$ KEZ, TU Liberec, Studentská 1402/2, 46117 Liberec 1, Czech Republic
}

\begin{abstract}
Air is a mixture of gases forming the gas wrap of Earth. It is formed by dry air, moisture and other pollutants. Dry air is a substance whose thermodynamic properties in gaseous state, as well as the thermodynamic properties of its main constituents in gaseous state, are generally known and described in detail in the literature. The liquid air is a bluish liquid and is industrially used to produce oxygen, nitrogen, argon and helium by distillation. The transition between the gaseous and liquid state (the condensation process, resp. boiling process), is usually displayed in the basic thermodynamic diagrams using the saturation curves. The saturation curves of all pure substances are of a similar shape. However, since the dry air is a mixture, the shapes of its saturation curves are modified relative to the shapes corresponding to the pure substances. This paper deals with the description of the dry air saturation curves as a mixture, i.e. with a description of the process of phase change of dry air (boiling process). The dry air saturation curves are constructed in the basic thermodynamic charts based on the values obtained from the literature. On the basis of diagrams, data appearing in various publications are interpreted and put into context with boiling process of dry air.
\end{abstract}

\section{Dry air composition}

Dry air is a mixture of gases, most of which are nitrogen $\mathrm{N}_{2}$ and oxygen $\mathrm{O}_{2}$. The composition of clean dry air does not change up to about $95 \mathrm{~km}$ above sea level and corresponds to the values in Table 1 according to the International Standard Atmosphere [1].

Table 1. Composition of clean dry air [1].

\begin{tabular}{|c|c|}
\hline gas & content of volume [\%] \\
\hline Nitrogen $\mathrm{N}_{2}$ & 78.084 \\
\hline Oxygen $\mathrm{O}_{2}$ & 20.9476 \\
\hline Argon $\mathrm{Ar}$ & 0.934 \\
\hline Carbon dioxide $\mathrm{CO}_{2}$ & $0.0314^{*}$ \\
\hline Neon $\mathrm{Ne}$ & 0.001818 \\
\hline Helium $\mathrm{He}$ & 0.000524 \\
\hline Krypton $\mathrm{Kr}$ & 0.000114 \\
\hline Xenon $\mathrm{Xe}$ & 0.0000087 \\
\hline Hydrogen $\mathrm{H}_{2}$ & 0.0005 \\
\hline Nitrogen monoxide $\mathrm{N}_{2} \mathrm{O}$ & $0.00005 *$ \\
\hline Methane $\mathrm{CH}_{4}$ & 0.0002 \\
\hline Ozone $\mathrm{O}_{3}$ in summer & up to $0.000007 *$ \\
in winter & up to $0.000002 *$ \\
\hline Sulphur dioxide $\mathrm{SO}_{2}$ & up to $0.0001 *$ \\
\hline Nitrogen Dioxide $\mathrm{NO}_{2}$ & up to $0.000002 *$ \\
\hline Iodine $\mathrm{I}_{2} \mathrm{I}_{2}$ & up to $0.000001 *$ \\
\hline Air & 100 \\
\hline
\end{tabular}

\footnotetext{
* Corresponding author: magda.vestfalova@tul.cz
}

(The content of the gas which is marked by the asterisk may undergo significant variations from time to time or from place to place.)

Table 2. Composition of clean dry air [2].

\begin{tabular}{|c|c|}
\hline gas & content of volume [\%] \\
\hline Nitrogen $N_{2}$ & 78.12 \\
\hline Oxygen $O_{2}$ & 20.96 \\
\hline Argon $A r$ & 0.92 \\
\hline Air & 100 \\
\hline
\end{tabular}

The dry air considered in [2] contains no carbon dioxide $\mathrm{CO}_{2}$ or other trace elements. The composition of clean dry air considered in [2] corresponds to the values in Table 2.

According to [2], errors due to measurement are greater than differences due to deviations in the air composition under consideration.

\section{Boiling of the components of dry air}

If we focus on the phase change between the liquid and gas phases, the parameters (i.e. pressure, temperature and volume or density) of the critical point $\mathrm{cr}$ and triple point $t r$ are given for $\mathrm{O}_{2}, \mathrm{~N}_{2}$ and Argon $\mathrm{Ar}$ in [2] see Table 3 and Table 4 . The critical point is the state with the highest possible pressure and at the same time the highest possible temperature at which boiling of the pure substance may occur. The triple point is conversely the state with the lowest possible pressure and at the 
same time the lowest possible temperature at which boiling of the pure substance may occur.

Table 3. Parameters of the critical point $\mathrm{cr}$ of dry air components [2].

\begin{tabular}{|c|c|c|c|}
\hline gas & $\begin{array}{c}\text { critical } \\
\text { point } \\
\text { temperature } \\
t_{c r}\left[{ }^{\circ} \mathrm{C}\right]\end{array}$ & $\begin{array}{c}\text { critical } \\
\text { point } \\
\text { pressure } \\
p_{c r}[\mathrm{MPa}]\end{array}$ & $\begin{array}{c}\text { specific volume } \\
\text { of critical point } \\
v_{c r}\left[\mathrm{~m}^{3} \cdot \mathrm{kg}^{-1}\right]\end{array}$ \\
\hline $\begin{array}{c}\text { Nitrogen } \\
N_{2}\end{array}$ & -146.958 & 3.3958 & 0.0031918 \\
\hline $\begin{array}{c}\text { Oxygen } \\
\mathrm{O}_{2}\end{array}$ & $-118.555^{\circ} \mathrm{C}$ & 5.046 & 0.0022928 \\
\hline Argon \\
$\mathrm{Ar}$
\end{tabular}

Table 4. Parameters of the triple point $t r$ of dry air components [2].

\begin{tabular}{|c|c|c|c|}
\hline gas & $\begin{array}{c}\text { triple point } \\
\text { temperature } \\
\left.t_{t r}{ }^{\circ} \mathrm{C}\right]\end{array}$ & $\begin{array}{c}\text { triple point } \\
\text { pressure } \\
p_{t r}[\mathrm{~Pa}]\end{array}$ & $\begin{array}{c}\text { specific volume } \\
\text { of triple point } \\
v_{t r}\left[\mathrm{~m}^{3} \cdot \mathrm{kg}^{-1}\right]\end{array}$ \\
\hline $\begin{array}{c}\text { Nitrogen } \\
N_{2}\end{array}$ & -209.999 & 12523 & 1.4830536 \\
\hline $\begin{array}{c}\text { Oxygen } \\
\mathrm{O}_{2}\end{array}$ & -218.789 & 146.33 & 96.543627 \\
\hline $\begin{array}{c}\text { Argon } \\
A r\end{array}$ & -189.3442 & 68891 & 0.246626 \\
\hline
\end{tabular}

The liquid-vapor saturation curve in the equilibrium $p-t$ diagram, which passes through the boiling points, begins in a triple point $t r$ and ends at a critical point $\mathrm{cr}$. For nitrogen $\mathrm{N}_{2}$ and oxygen $\mathrm{O}_{2}$, it is possible to find boiling parameters in [3], i.e. for each temperature it is possible to find the pressure at which boiling occurs. For argon Ar, the required data was searched in [4]. From the above data, a saturation curve in the equilibrium phase $p-t$ diagram can be constructed for each of the dry air components - see Figure 1.

During the change phase at constant pressure of the pure substance, i.e. nitrogen $\mathrm{N}_{2}$, oxygen $\mathrm{O}_{2}$ and argon $A r$, the temperature does not change, but the volume increases. In [3], for nitrogen $\mathrm{N}_{2}$ and $\mathrm{O}_{2}$ for each temperature, it is possible to find not only pressure but also density (resp. the specific volume) at the beginning and at the end of boiling process. From these data, for each of the components, a curve connecting the saturated liquid states (liquid saturation curve) and a curve connecting the saturated vapor state (vapor saturation curve) can be constructed in the $p-v$ diagram, see Figure 2. The critical point for each of these curves lies at the "highest" point of the corresponding saturation curve, i.e. at a point corresponding to the maximum pressure at which the substance can boil. The diagram also shows the boiling process for both gases for several different temperatures (from $-210^{\circ} \mathrm{C}$ to $\left.-120^{\circ} \mathrm{C}\right)$.

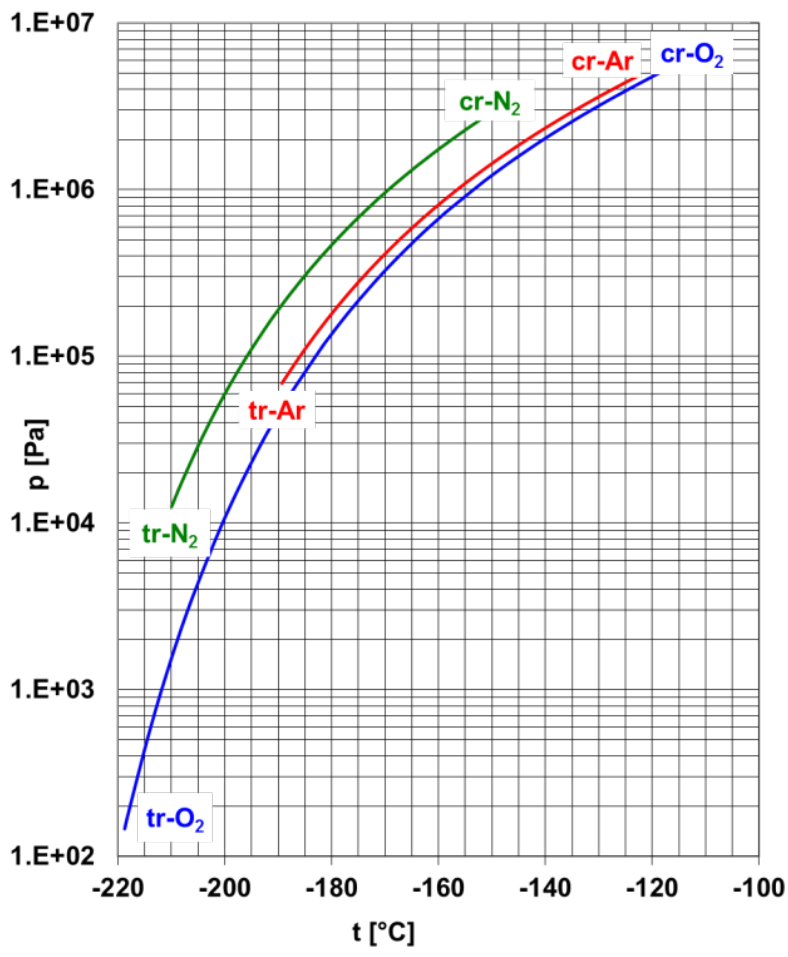

Fig. 1. Liquid-vapor saturation curve in the phase $p-t$ diagram for the three most important components of dry air: nitrogen $\mathrm{N}_{2}$ - green, oxygen $\mathrm{O}_{2}$ - blue, argon $\mathrm{Ar}$ - red; $\mathrm{cr}$ critical point, $t r$ - triple point.

\section{Phase change of dry air}

Boiling of mixture has a different course from the boiling of the pure component [5], [6]. Let us assume the binary mixture only (we only consider nitrogen $N_{2}$ and oxygen $\mathrm{O}_{2}$ ). By isobaric heating of the binary liquid mixture at a certain temperature we reach the state in which the mixture begins to boil (point of starting the boiling). The point of starting the boiling at the given pressure is uniquely determined by the boiling point of the components at the corresponding pressure and by the proportional composition of the individual components in the mixture. During the boiling of the liquid phase, the more volatile component of the mixture - in our case nitrogen $N_{2}$ - evaporates more intensively. This means that the emerging gas phase will be "richer" about the nitrogen $N_{2}$, on the other hand the remaining liquid phase will be "poorer" about nitrogen $N_{2}$. Thus, the composition of the liquid phase varies - in the liquid phase there is a higher oxygen ratio than it was in the beginning of boiling. If the boiling should continue, the temperature must gradually increase - i.e. the boiling (phase change) of the mixture at constant pressure does not proceed under a constant temperature but with a gradual increase of temperature! At a certain temperature, all the liquid phase is converted to the gas phase - the boiling is finished. The boiling end temperature is higher than the starting boiling temperature at a given pressure, and is again uniquely 
determined by the boiling point of the individual components at the corresponding pressure and at the relative proportion of the individual components in the mixture.

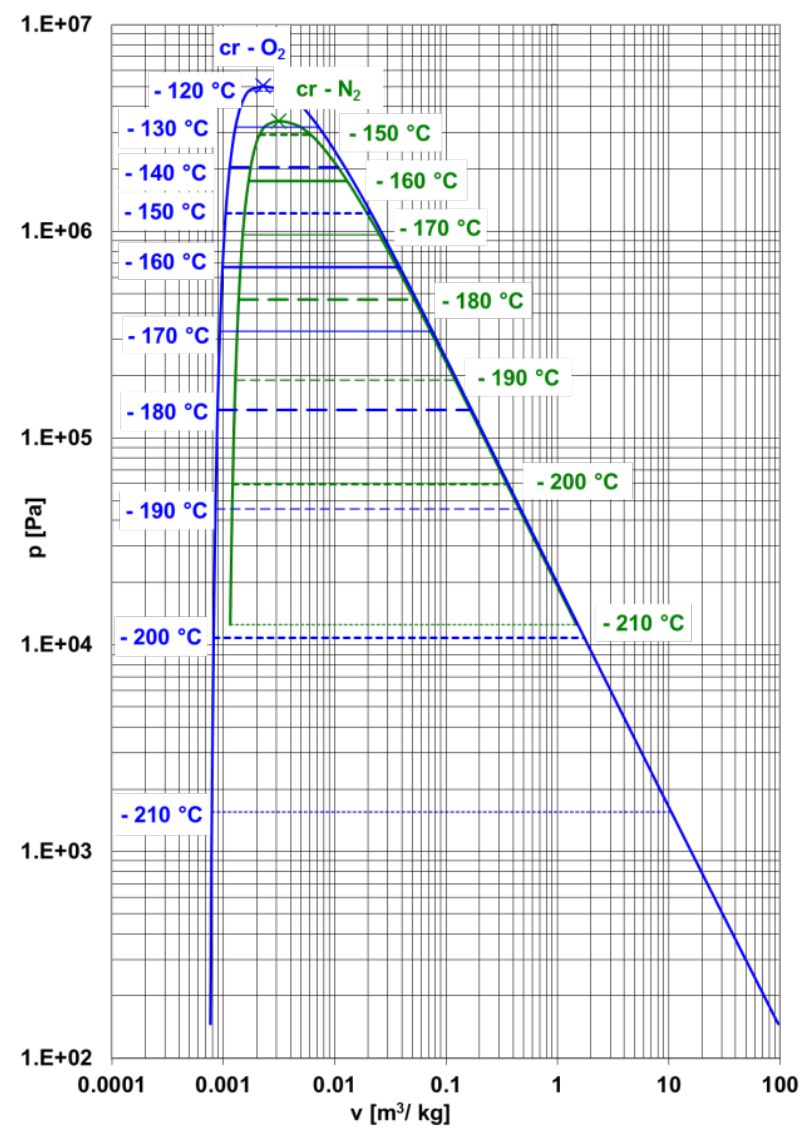

Fig. 2. Liquid and vapor saturation curves in $p-v$ diagram for dry air components: nitrogen $\mathrm{N}_{2}$ - green, oxygen $\mathrm{O}_{2}$ - blue; cr -critical point.

In the equilibrium phase $p-t$ diagram, the boiling of the mixture of given composition is not represented by a single curve (in which points the boiling would run at constant pressure and temperature) but by a loop, on the left branch of which are the starting boiling points and on the right branch of which are the boiling end points for the mixture of this composition. For dry air, it is possible to find the start and end melting states parameters in [2]. Figure 3 shows an equilibrium phase $p-t$ diagram with a plotted saturation curve of oxygen $\mathrm{O}_{2}$, nitrogen $\mathrm{N}_{2}$ and dry air, i.e. a mixture of oxygen $\mathrm{O}_{2}$ and nitrogen $\mathrm{N}_{2}$ containing $23 \%$ by volume of oxygen $\mathrm{O}_{2}$. For mixtures of oxygen $\mathrm{O}_{2}$ and nitrogen $N_{2}$ of another composition, the loops in the equilibrium phase $p-t$ diagram would have a different shape.

If we construct an envelope of saturation loops for different compositions, we would obtain a curve of socalled pseudocritical states, originating from the oxygen $\mathrm{O}_{2}$ critical point and ending at critical point nitrogen $N_{2}$ (the dotted line in Figure 3). The pseudocritical state, unlike the critical state, is not defined by the highest possible pressure of boiling and the highest possible temperature of boiling (see Table 5). The pseudocritical state is defined as envelope curve of the saturation loops.

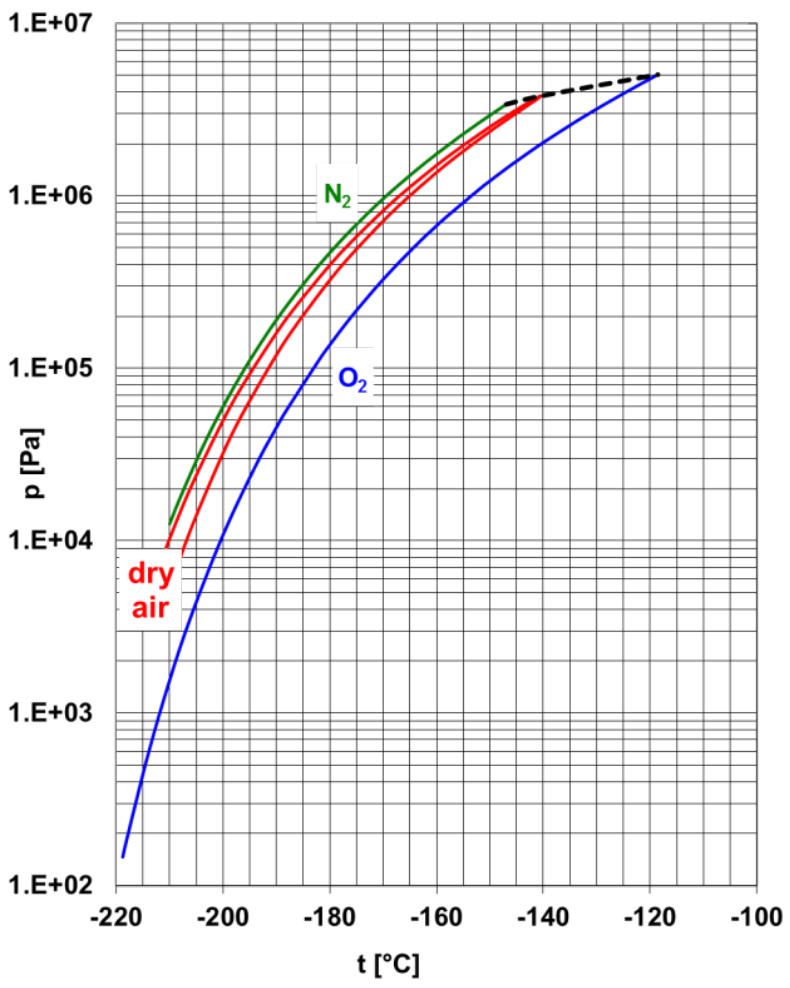

Fig. 3. Liquid-vapor saturation curve in the phase $p-t$ diagram for the dry air (red loop), nitrogen $N_{2}$ (green curve) and oxygen $O_{2}$ (blue curve); pseudocritical states of the mixture of nitrogen $\mathrm{N}_{2}$ and oxygen $\mathrm{O}_{2}$ - black dotted curve.

Looking at the top of the dry air curve (see Figure 4), we can see that in pseudocritical condition the pressure is lower than the maximum pressure at the saturation loop, i.e. if the boiling of air at the pseudocritical pressure $p=3.7860 \mathrm{MPa}$ would run, then at the beginning of boiling, the air temperature (at that point is the air in the whole volume in liquid phase) would correspond to the pseudocritical temperature $t=-140.6194^{\circ} \mathrm{C}$, but the temperature would increase during boiling. The boiling could however take place at a higher pressure: the maximum pressure, at which the elementary boiling process (phase change) could take place in the air, is $p=3.7891 \mathrm{MPa}$. The corresponding temperature would be $t=-140.5465^{\circ} \mathrm{C}$ (i.e. higher than pseudocritical). This state is called maxcondenbar state.

Looking at the top of the dry air curve (see Figure 4), we can also see that in pseudocritical condition the temperature is lower than the maximum temperature at the saturation loop. When we observe a process of phase change during isothermal expansion, so the maximum temperature, at which the elementary phase change could take place in the air, is $t=-140.5188^{\circ} \mathrm{C}$. The corresponding pressure would be $p=3.78502 \mathrm{MPa}$ 
(i.e. lower than pseudocritical). This state is called maxcondentherm state.

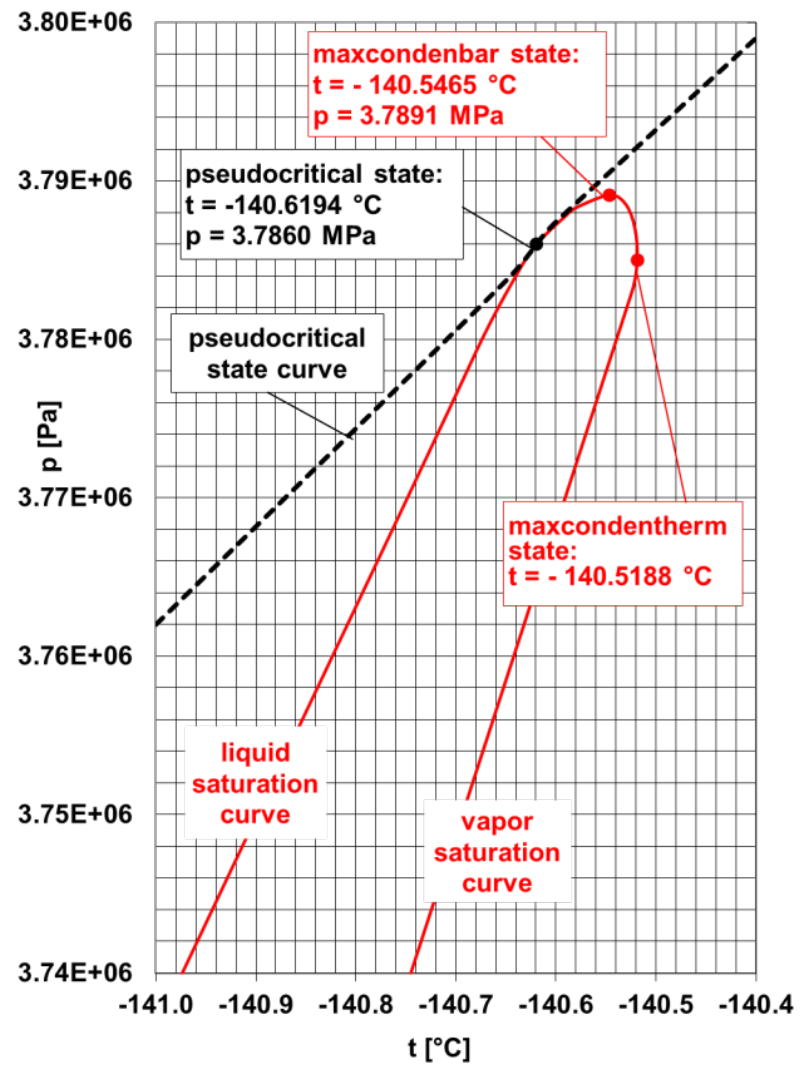

Fig. 4. Liquid and vapor saturation curves in p-v diagram for dry air components: nitrogen $\mathrm{N}_{2}$ - green, oxygen $\mathrm{O}_{2}$ - blue.

Table 5. Parameters of the pseudocritical point of air [2].

\begin{tabular}{|l|l|l|l|}
\hline \multicolumn{1}{|c|}{ point } & $\begin{array}{c}\text { temperature } \\
{\left[{ }^{\circ} \mathrm{C}\right]}\end{array}$ & $\begin{array}{c}\text { pressure } \\
{[\mathrm{MPa}]}\end{array}$ & $\begin{array}{c}\text { specific } \\
\text { volume } \\
v_{t r}\left[\mathrm{~m}^{3} \cdot \mathrm{kg}^{-1}\right]\end{array}$ \\
\hline "Critical" & -140.6194 & 3.7860 & 0.0029188 \\
\hline Maxcondentherm & -140.5188 & 3.78502 & 0.0033052 \\
\hline Maxcondenbar & -140.5465 & 3.7891 & 0.0031125 \\
\hline
\end{tabular}

The difference in the course of the phase change of the mixture from the phase change of the pure substance can also be seen in the $p-v$ diagram: during the phase change (for example during boiling) at constant pressure, volume of mixture increases but temperature of the mixture increases too. Conversely, during the phase change (for example from a liquid phase to a gaseous phase) under constant temperature conditions, volume of mixture increases but pressure of the mixture decreases. In Figure 5, the saturation curves of the beginning and end of the boiling process are plotted in the $p-v$ diagram for dry air (and for comparison for nitrogen $\mathrm{N}_{2}$ and oxygen $\mathrm{O}_{2}$ too), including the network of isotherms.

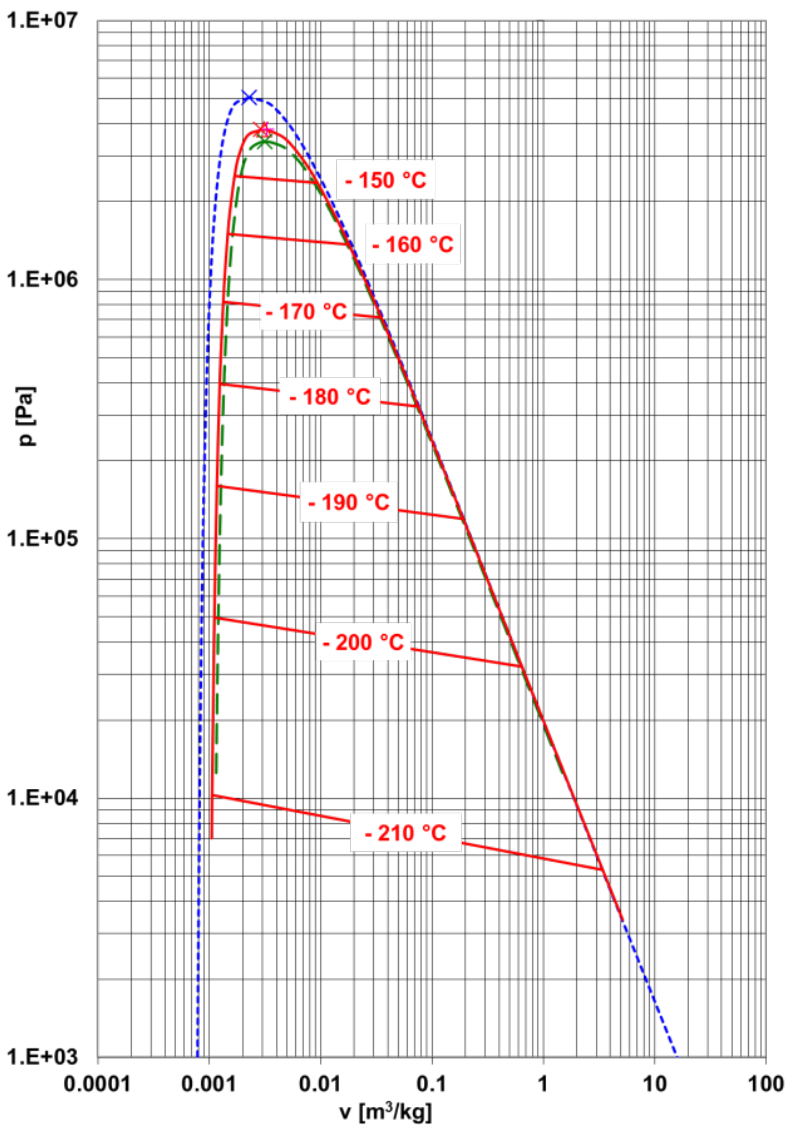

Fig. 5. Liquid and vapor saturation curves in the phase $p-t$ diagram for the dry air.

\section{Conclusion}

Dry air is a mixture of many gases. Except for nitrogen $\mathrm{N}_{2}$ and oxygen $\mathrm{O}_{2}$, gases are present in the air in a small amount and their effect on the thermodynamic behavior of the air can be neglected. Thus, from a thermodynamic point of view, dry air can be considered as a binary mixture. Changing the phase of the mixture takes place (at a constant pressure) while changing the temperature. Therefore, in the equilibrium phase $p-t$ diagram of dry air, the saturation curve passes in the saturation surface bounded by saturation loop. On its lower branch are the points of starting of phase change and on the upper branch there are the points of the ending of phase change. At the liquid-vapor saturation curve of dry air, there is an interesting area near "critical" point with three important points: a pseudocritical point, a point corresponding to the maximum possible condensing temperature maxcondentherm point, and a point corresponding to the maximum possible condensing pressure - maxcondenbar point. 


\section{Acknowledgement}

This publication was written at the Technical University of Liberec as part of the project SGS 21135 with the support of the Specific University Research Grant, as provided by the Ministry of Education, Youth and Sports of the Czech Republic in the year 2017.

\section{References}

1. International Standard Atmosphere, ISO 2533:1975, International Organization for Standardization (1975)

2. E, W. Lemmon, R. T. Jacobsen, S. G. Penoncello, D. G. Friend, Journal of Physical and Chemical Reference Data, 29, 3: 331-385 (2000)

3. VDI Wärmeatlas, Springer (2006)

4. J. Šesták, J. Bukovský, M. Houška, Thermal processes - transport and thermodynamic data, CTU Publishing House (in Czech) (1993)

5. E. Hála, J. Pick, V. Fried, O. Vilím, Equilibrium between liquid and vapour, Foreign Literature Publishing House (in Russian) (1962)

6. W. J. Moore, Physical Chemistry, State publishing house of technical literature (in Czech) (1972) 